\title{
Super Cyclone SIDR 2007: Climate Change Adaptation Mechanisms for Coastal Communities in Bangladesh
}

\author{
Tapan Sarker ${ }^{1}$ and Mehdi Azam ${ }^{2}$ \\ ${ }^{1}$ Asia Pacific Centre for Sustainable Enterprise, Griffith University, 226 Grey Street, \\ South Brisbane QLD 4101, Australia. E-mail: tapan.sarker@griffith.edu.au \\ ${ }^{2}$ Macquarie Law School, Macquarie University, Sydney, Australia. E-mail: mehdi.azam@mq.edu.au
}

\begin{abstract}
Cyclone SIDR ${ }^{\mathrm{i}}$ hit the coastal districts of Bangladesh on November 15, 2007 in the evening when it started crossing the country from northern Bay of Bengal with high tidal surges and strong winds of up to $260 \mathrm{~km} / \mathrm{hr}$. This study has been undertaken to assess the severity of the damage caused by SIDR, and identify causes of such cyclonic storms in recent years in order to suggest possible adaptive measures for the coastal people to cope with such situations in the future. The study reveals that both natural and human induced factors are responsible for such devastating catastrophes. The study suggests a number climate change adaptation and mitigation options that can be taken to reduce the severity of damages caused by cyclones in the coastal areas of Bangladesh. These include: developing an early warning system; constructing adequate cyclone shelters and tree plantations in the remote coastal areas; constructing structured and fortified houses and livestock shelters; livelihood diversification; and building awareness in the community regarding the impacts of changing climatic conditions in the coastal areas of Bangladesh.
\end{abstract}

Keywords: Cyclone SIDR, Climate change adaptation, Livelihood diversification.

\section{Introduction}

The years of 1970, 1991 and 2007 will be remembered for years to come for highly devastating cyclonic storms in the Bay of Bengal, which affects present Bangladesh and West Bengal. Bangladesh in particular has had to face a host of natural calamities every year, due to its geographical setting and geomorphic characteristics. Its coastal areas especially have regularly suffered the loss of valuable lives and property. Statistics show that revealed that 16 percent of cyclones created in the Bay of Bengal hit the coastal areas of Bangladesh and approximately six out of nine depressions formed in the Bay of Bengal normally cross the belt of Bangladesh every year (Khan and Sen, 2000). Following this trend, there is a probability that 1.12 cyclones will occur in any given year. In the last 30 years, nearly 900,000 people have died due to disastrous cyclones. Further, most of these severe cyclones took 
place during the latter part of the year (i.e. during October and November), which is the harvesting period for the main rice crop, Aman.

In the afternoon of November 15, 2007, the super cyclone SIDR started its devastation in Bangladesh. With wind speeds of between $180-260 \mathrm{~km} / \mathrm{hr}$, the cyclone impacted most of Bangladesh, especially coastal districts near the Bay of Bengal with heavy rainfall (The Daily Star, November 15, 2007). The 'eye' of the cyclone passed through several coastal districts and terrible damage took place in those districts. Damage included huge loss of life, damage to houses, livestock, crops, educational institutions, roads and embankments have been reported from 1811 unions $^{\text {ii }}$ of 200 upazilas $^{\text {iii }}$ in 31 districts. Official sources reported approximately 3500 deaths, total or partial destruction of more than 80 percent of thatched houses, damage to 70 percent of the near-harvest rice paddies, 60 to 70 percent of fisheries and huge numbers of livestock. Economic loss was estimated to be worth around Tk. 6,000 Crore which may eventually reach Tk. 16100 Crore (The Daily Ittefaq, January 08, 2008).

On a global scale, coastal regions and low-lying areas are projected to be increasingly vulnerable to risks associated with climate change and sea-level rise. The mega-deltas of Africa and Asia and a range of small low lying islands, are projected to be most at risk with regards to sea level rise and associated flooding events. Bangladesh, as one of the world's many densely populated, low lying areas, have low adaptive capacity and face climate related challenges such as regular cyclone and storm surge events (IPCC, 2007).

Although the impact of these natural disasters could be mitigated by adaptation, the adaptive capacity of coastal populations in Bangladesh is low because it represents one of the most densely populated and socio-economically poor regions in the world (Ali, 1996). Further, climate change adds a new dimension to community risk and vulnerability for the coastal people in Bangladesh. Although the magnitude of these changes may appear to be small, they could substantially increase the frequency and intensity of existing climatic events such as cyclones (MoFDM, 2007b). Tropical cyclones (TCs) are the most violent of the organized convective systems. The destructive effects of TCs are caused by the intense precipitation and the very strong winds, which can produce surges and a rise of sea levels in coastal areas. The socio-economic consequences for countries affected by TCs can be dramatic: large loss of human life, and destruction of infrastructures and crops (Royer et al., 1998). Preventing the occurrence of TCs and associated storm surges is not possible as they are naturally occurring. Climate change enhances the threat of natural disasters by increasing the severity of these events. It is thus argued that adaptation represents the only feasible option especially for acutely vulnerable coastal regions in Bangladesh (Ali, 1996). This study has been undertaken to assess the severity of damage caused by SIDR, identify causes of such cyclonic storms in the recent years and suggest possible adaptive measures for the coastal people to cope with such situations in the future. 


\section{Formation of Super Cyclone SIDR 2007}

On November 2007, an area of disturbed weather developed southeast of the Andaman Islands, with a weak low-level circulation near the Nicobar Islands. Initially moderate upper-level wind shear inhibited organization, whereas strong diffluence aloft contributed to developing convection (Charlie Forecast Team, 2007a). Vertical wind shear decreased greatly as the circulation became better defined, and a Tropical Cyclone Formation Alert was issued on November 11, 2007, while the cyclone was located a short distance south of the Andaman Islands (Charlie Forecast Team, 2007b). Then early on November 12, 2007, the cyclonic storm SIDR began to intensify quickly as it moved slowly northwestward and the India Meteorological Department (IMD) upgraded it to a severe cyclonic storm later that day (Webcite, 2007a) and a very severe cyclonic storm early the next day (Webcite 2007b) (Fig. 1). On the morning of November 15, the cyclone intensified to reach peak winds of $215 \mathrm{~km} / \mathrm{hr}$ according to the IMD (Webcite, 2007c), and a peak of $250 \mathrm{~km} / \mathrm{hr}$ according to the Joint Typhoon Warning Center best track (JWTC, 2007). SIDR officially made landfall around 1700 UTC later that day, with sustained winds of $215 \mathrm{~km} / \mathrm{hr}$ and weakened quickly after landfall on late night of November 16, 2007 (Webcite, 2007d) (Fig. 1).

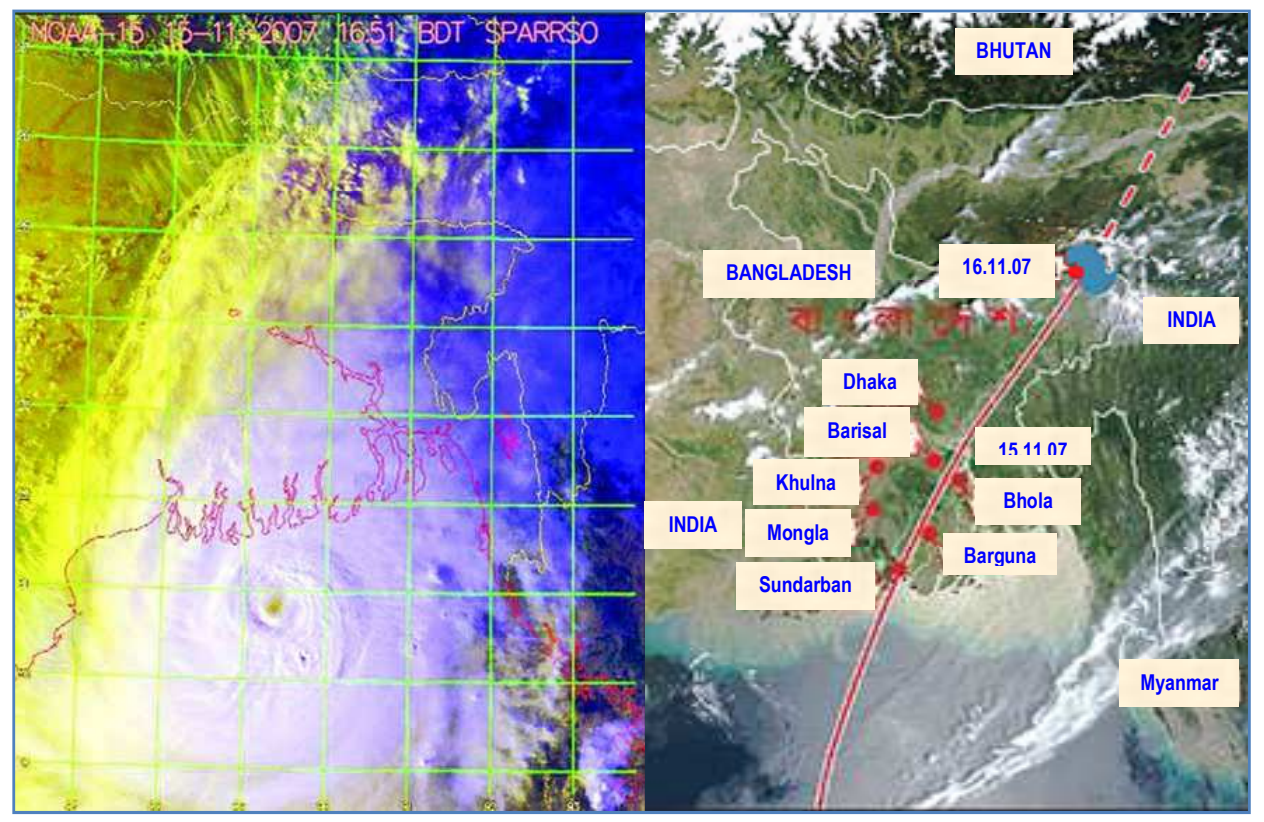

Figure 1 Cyclone SIDR formation and path of devastation (SPARRSO, 2007). 


\section{Devastation Caused by SIDR 2007}

In the aftermath of Cyclone SIDR 2007, huge loss of life, damage to houses, livestock, crops, educational institutions, roads and embankments was reported (see Table 1 and Table 2). This section outlines the reported loss of life, loss of livestock, damage to houses, estimated crop losses, losses incurred by the shrimp industry, damage to infrastructure and the overall economic impact on livelihoods. Table 1 provides figures reported in the official SIDR 2007 damage report, prepared by the Ministry of Food and Disaster Management (MFDM) Relief Control Cell (RCC). Table 2 provides figures for damage reported for selected areas per Upazila, sourced from the 2008 Prodipan Damage Assessment Report for SIDR. Both these tables have been included to provide a broad perspective of the damage incurred (Table 1) and a more detailed perspective of the areas acutely affected by SIDR (Table 2).

\subsection{Loss of life and livestock}

In the aftermath of SIDR, there were over 2,744,081 people in some 780 unions living in inhumane conditions as the cyclone rendered most of them homeless by demolishing 5,649,67 houses completely and 9,571,10 partially. Overall 3,363 deaths have been confirmed by the government, 871 people declared missing, and roughly 55,282 people were injured (MoFDM, 2007a), although non-governmental sources claimed deaths could be around 10,000 (Rahman, 2007).

In addition, about 1,778,507 livestock deaths were reported after the devastation. Loss of cows reached 0.2 million, loss of goats 0.5 million, loss of rams/sheep 0.1 million, loss of buffalos 10-12 thousand, and a significantly large loss of poultry wild birds and animals was also reported (MoFDM, 2007a).

\subsection{Damage of house}

Huge numbers of houses were fully damaged and washed away and those which were not blown away became completely unusable. More than 1, 500,00 houses were either fully or partially damaged (UNDP, 2008). According to government estimates, 5, 649,67 houses were fully damaged and 9,57,110 were partially damaged in 31 affected districts (MoFDM, 2007a). The four most affected districts (i.e. Barguna, Bagerhat, Pirojpur, Patuakhali) accounted for 331,498 (58.68 percent) fully damaged households and 439,604 (45.93 percent) partially damaged households (see Table 1).

\subsection{Estimated crop loss}

Loss of Aman rice production was estimated at approximately 1 million tonnes, which makes up around 41 percent of the total rice production of the country. 


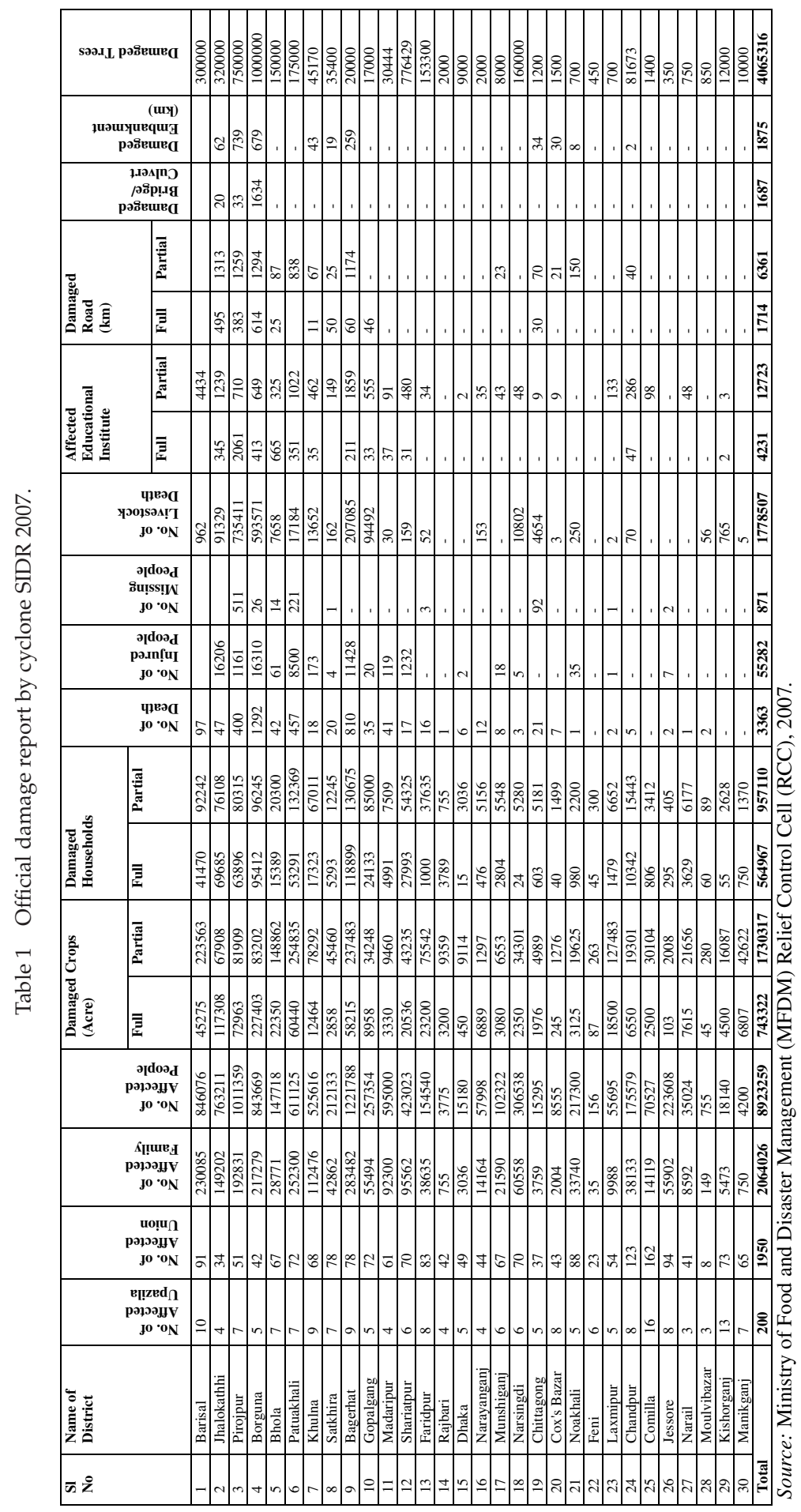




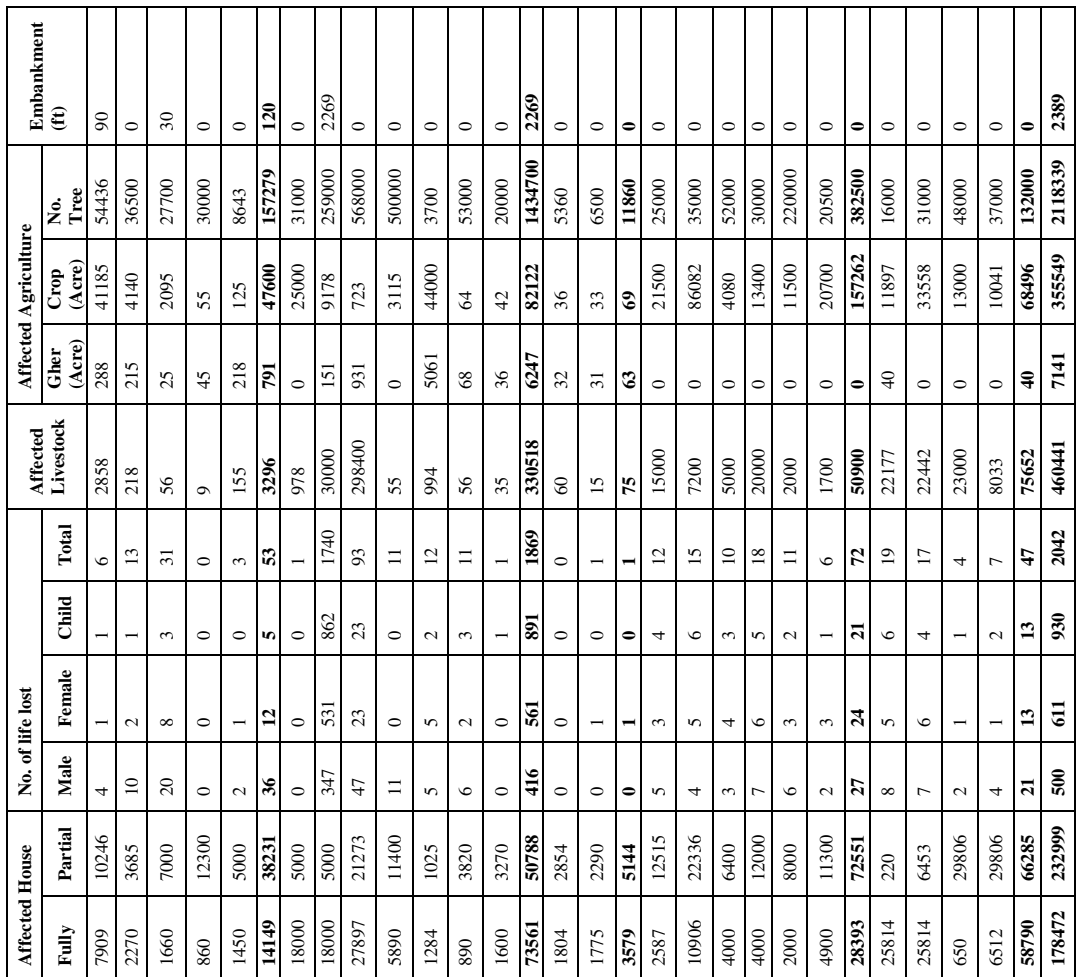

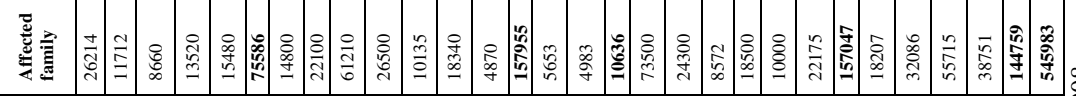

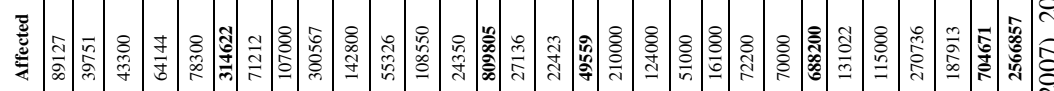



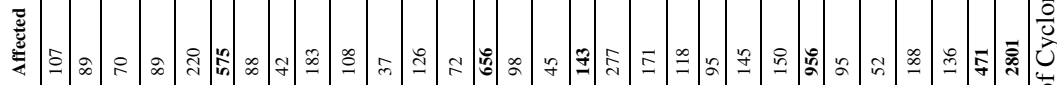

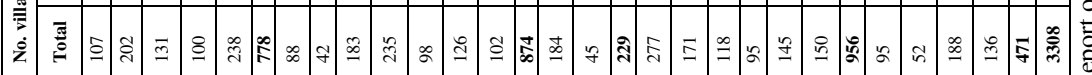

$\frac{\stackrel{0}{\pi}}{\frac{\pi}{\pi}}$

\begin{tabular}{|c|c|c|c|c|c|c|c|c|c|c|c|c|c|c|c|c|c|c|c|c|c|}
\hline 胥 & $\because \cong$ & -1 & $0=$ & $\pm f$ & & $=$ & $\cong$ & $r-$ & - & in 6 & in & $\Rightarrow$ & \pm & $a$ in & - & $=2$ & 0 & 09 & 2 & in & ส \\
\hline تج & $\frown \cong$ & -1 & $0=$ & $\pm f$ & 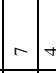 & $=$ & $\cong$ & 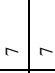 & - & in $\infty$ & 0 & \pm & $= \pm$ & a & - & $=2$ & 0 & 09 & 2 & & \\
\hline & 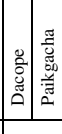 & 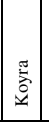 & & 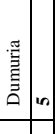 & 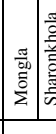 & 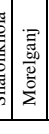 & 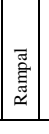 & 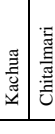 & 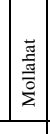 & 爵 & 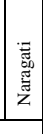 & & 嗉 & 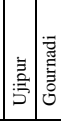 & 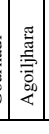 & 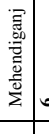 & 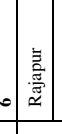 & 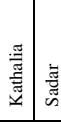 & \begin{tabular}{|l}
$\frac{2}{0}$ \\
$\frac{0}{2}$ \\
\end{tabular} & & . \\
\hline & & 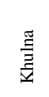 & & & & & 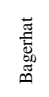 & & & & 䨗 & & & 离 & & & & 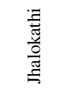 & & & \\
\hline & & $\overline{0}$ & & 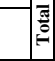 & & & 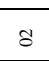 & & & F & 8 & 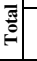 & & t & & & & 3 & & & 5 \\
\hline
\end{tabular}


Moreover, SIDR also damaged standing crops on around 0.5 million hectares of land in the south and south-western districts. This caused a loss of around 0.6 tonnes of food-crops, particularly the Aman (UNDP, 2008).

\subsection{Estimated loss in shrimp industry}

Thousands of the shrimp cultivators in the coastal belt have faced catastrophe after the cyclone. SIDR washed away the key production areas of the country's second largest export industry. In Morelgonj and Sharonkhola upazilas alone, more than 90 percent of some 5000 shrimp cultivation farms were demolished by the storm surge. Shrimp farms in the three southern districts Bagerhat, Satkhira and Khulna, that were severely ravaged by SIDR, suffered a loss of Tk. 1750 (BFFEA, 2008). The country's second largest cash cow, shrimp or frozen food industry, earned USD 515 million from exports during the fiscal year 2006-07 (ReliefWeb, 2011).

\subsection{Estimated damage in infrastructure}

Around 10,000 institutions in 30 districts have been seriously disrupted, which included 4489 primary schools and 3750 high schools, colleges, madrashas ${ }^{\mathrm{v}}$. About 4,231 educational institutions in 30 districts, especially Bagerhat, Barguna, Patuakhali, Pirojpur, Bhola, Jhalakathi and Barisal, were completely damaged by SIDR (MoFDM, 2007a), meaning that only a few brick-built institutions survived the cyclone's impact. Further, 12,723 educational institutions were partially damaged. About 8,075 km roads, 687 bridges and culverts, and 2,290 embankments were partially damaged (UNDP, 2008).

Damage to infrastructure was also massive. About 20 thousand kilometres of power supply lines (out of 25 thousand kilometres under different Palli Biddut Samity (PBS) suppliers), were damaged (REB 2008).

\subsection{Impact on livelihoods}

Livelihoods were seriously impacted by the damage to income generating assets, such as loss of fishing boats and gear, and industrial equipment. A total of 567,000 people were affected in their employment by SIDR, and of these, 160,000(28\%) temporarily or permanently lost their sources of income in non-agricultural establishments, along with another 134,000 (23\%) self-employed workers (ILO, 2008).

\section{Tropical Cyclones and Global Climate Change}

In Bangladesh, tropical cyclones usually originate in the Bay of Bengal, proceed to the coast, hit the coast and gradually turn into weak land depressions. However, more recently the cyclones have been remaining over the land for a longer period 
Table 3 Frequency of tropical cyclones.

\begin{tabular}{lll}
\hline From - to & $\begin{array}{l}\text { Duration } \\
\text { (Years) }\end{array}$ & $\begin{array}{l}\text { Frequency } \\
\text { of } \\
\text { Cyclones }\end{array}$ \\
\hline $1795-1845$ & 50 & 3 \\
$1846-1896$ & 50 & 3 \\
$1897-1947$ & 50 & 13 \\
$1948-2009$ & 61 & 53 \\
Total & 211 & 72 \\
\hline \multicolumn{2}{c}{ Source: } & Bangladesh Meteorological \\
\multicolumn{2}{c}{ Department, 2010. }
\end{tabular}

of time and causing more harm to the communities. In general, cyclonic storms and tidal surges - including SIDR - occur naturally, although anthropogenic factors have also reportedly had an impact on their formation. These anthropogenic factors include increasing sea surface temperature (SST), and polar ice melting due to global warming and the subsequent expansion of ocean water, which has been spread to the low lying countries. It is widely recognized that global warming may have an impact on the formation, increased frequency and intensity of tropical cyclones. The Bangladesh Meteorological Department (BMD) has illustrated this trend, reporting a sharp increase in both the frequency and intensity of tropical cyclones in recent years (Table 3 and Table 4 ).

According to recent reports, an increase in $2{ }^{\circ} \mathrm{C}$ in Sea Surface Temperature (SST) would likely to cause an increase in the probability of cyclone formation from depressions in the Bay of Bengal (Ali, 1996; Agrawala et al., 2003). The reports also suggest that cyclone tracks may shift under climate change - meaning that an increasing number of cyclonic storms will be likely to hit Bangladesh and the possibility of an increase in peak intensities of cyclones may be 5-10 percent higher. Potential tidal surges and the associated precipitation are also projected to increase between 20 to 30 percent more than those observed currently. The probability of an increased SST will cause an increase in the formation of low pressure and depressions in the Bay of Bengal, resulting in rough oceanic waves along the coastal zone. Large increases of cyclones are caused mainly by the factor representing the enhanced oceanic energy available to support tropical cyclone formations. Other thermal components add smaller positive contributions through the enhanced evaporation and lower atmospheric stability caused by the oceanic warming. The atmosphere is globally warmer and less stable leading to a factor of 1.7 increases in the thermal potential. The dynamic part, on the other hand, tends to limit the cyclogenesis increase. The strong reduction of the dynamic potential on the poleward sides of the cyclogenesis zones compensates the enhanced area of oceanic surface temperature above $26^{\circ} \mathrm{C}$ (Royer et al., 1998). Theoretical projections show that a $1^{\circ} \mathrm{C}$ rise in SST will increase the cyclone intensity by approximately 4 
Table 4 Major storms since 1822.

\begin{tabular}{llll}
\hline Date of Occurrence & $\begin{array}{l}\text { Max. Wind } \\
\text { Speed (Km/hr) }\end{array}$ & $\begin{array}{l}\text { Storm Surge } \\
\text { Height }(\mathrm{ft})\end{array}$ & Death Toll \\
\hline May 1822 & - & - & 40,000 \\
October 31, 1876 & - & 40 & 200,000 \\
October 09, 1960 & 162 & 10 & 3,000 \\
October 30-31, 1960 & 210 & $15-20$ & 10,000 \\
May 09, 1961 & 146 & $8-10$ & 11,468 \\
May 30, 1961 & 146 & $20-29$ & - \\
May 28-29, 1963 & 203 & $14-17$ & 11,520 \\
May 11, 1965 & 162 & $12-24$ & 19,279 \\
December 15, 1965 & 217 & $8-11$ & 873 \\
October 01, 1966 & 139 & $19-22$ & 850 \\
November 12, 1970 & 224 & $19-32$ & 500,000 (Official); \\
& & & $1,200,000$ (Unofficial) \\
December 09, 1973 & 122 & $5-15$ & 183 \\
November 28, 1974 & 162 & $7-16$ & 50 \\
May 24-25, 1985 & 154 & $10-15$ & 11,069 \\
November 29, 1988 & 162 & $5-10$ & 2,000 \\
April 29-30, 1991 & 225 & $20-25$ & 138,882 \\
May 02, 1994 & 200 & - & 170 \\
May 19, 1997 & 232 & $10-15$ & 155 \\
May 26, 1997 & 150 & 10 & 70 \\
November 15, & $180-250$ & $10-15$ & 3363 (Official) \\
2007 (SIDR) & & & 5000 (Unofficial) \\
\hline Soure: The Dily Stral & & \\
& & & \\
\hline
\end{tabular}

Source: The Daily Star, November 16 2007; MoFDM, 2007;

BMD, 2007; EU, 1998.

percent, a $2^{\circ} \mathrm{C}$ rise by 10 percent and a $4^{\circ} \mathrm{C}$ rise by 22 percent (Emanuel, 1987). An increase in cyclone intensity can also cause an increase in tidal surge heights and the horizontal extent of flooding and subsequent water logging. However, the tidal surge height of SIDR was comparatively low (10-15ft) considering its intensity because it hit the coast during low tide. A model analysis by Ali, (1996) shows that tidal surge heights will increase by 21 percent and 47 percent for a corresponding rise in SST by $2^{\circ} \mathrm{C}$ and $4^{\circ} \mathrm{C}$ respectively for a particular location along the north eastern coast of Bangladesh.

\subsection{Melting of polar ice and sea level rise}

Rising temperatures expand the ocean volume in two ways. Firstly, global warming melts mass volumes of ice in the polar region and secondly, it causes thermal expansion of water of the ocean (Sarwar, 2005). Wigley and Raper, (1987) posit that the relative contributions of thermal expansion and ice melting to this sea level rise are uncertain and estimates vary widely. Estimates for the contribution of 

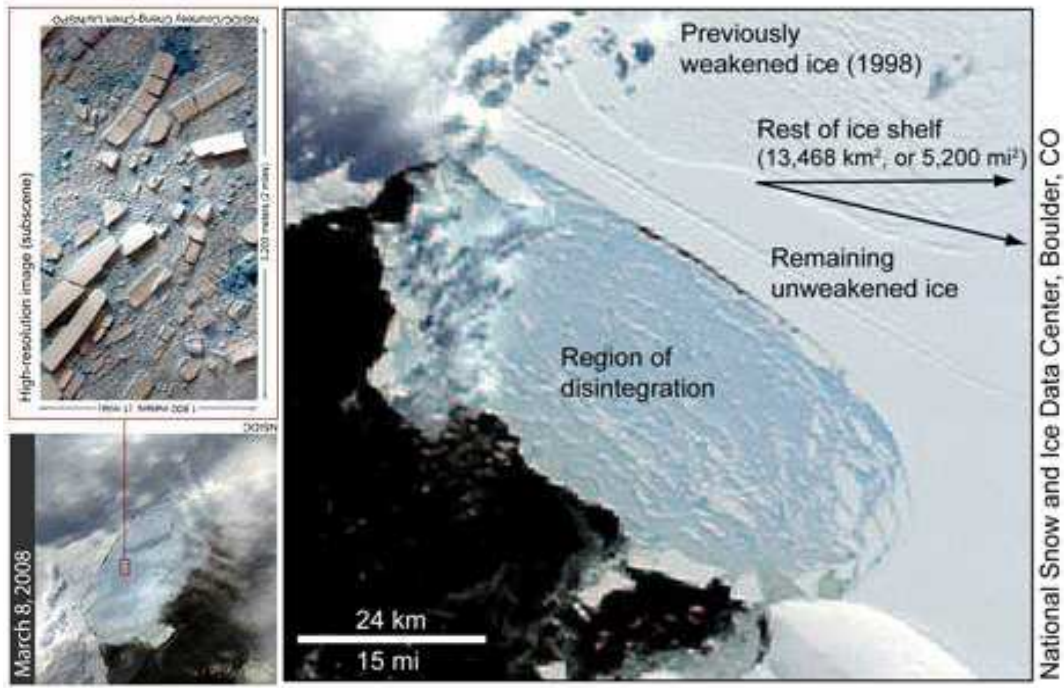

Figure 2 Satellite image of Wilkins Ice Shelf disintegration-March 8, 2008 (NSIDC, 2008).

thermal expansion to seal level rise range from, minimal impact (less than polar ice melting), approximately equal impact (of thermal expansion and polar ice melting) to dominant impact (thermal expansion as the dominant factor leading to sea level rise). Regardless of these estimations, these two factors increase the overall volume of ocean water on the earth and contribute to the sea level rise that ultimately poses a serious threat to the survival of low-lying and small island nations. Velicogna and Wahr, (2006) measured variations in the Antarctic ice sheet between 2002 and 2005. The study indicates that the mass of the West Antarctic ice sheet decreased significantly, at a rate several times greater than assumed by the IPCC in its Third Assessment Report. Climate change could possibly cause the West Antarctic ice sheet to slide into the ocean, which would raise average sea level by approximately 5 to 6 meters, even if the ice sheet did not melt (The World Bank, 2008). Satellite imagery from the National Snow and Ice Data Center (NSIDC) at the University of Colorado at Boulder reveals that a 13,680 square kilometer (5,282 square mile) ice shelf has begun to collapse because of rapid climate change in a fast-warming region of Antarctica. The Wilkins Ice Shelf is a broad plate of permanent floating ice on the southwest Antarctic Peninsula, about 1,000 miles south of South America. In the past 50 years, the western Antarctic Peninsula has experienced the biggest temperature increase on Earth, rising by $0.5^{\circ} \mathrm{C}\left(0.9^{\circ} \mathrm{F}\right)$ per decade (Fig. 2).

A study undertaken by the SMRC (1999) reveals that between 1977 and 1998 the rate of sea level rise was $4.00 \mathrm{~mm} / \mathrm{yr}$ at Hiron Point, $6.0 \mathrm{~mm} / \mathrm{yr}$ at Char Changa and $7.8 \mathrm{~mm} / \mathrm{yr}$ at Cox's Bazar. These figures are many times higher than the mean rate of global sea level rise over the last 100 years. The figures also illustrate the important effects of regional tectonic subsidence. Tidal ranges will increase due 
to sea level rise and compound the interaction between tidal surges and tides and therefore increase the amount of water carried to the coast during cyclones. These factors make the coastal regions of Bangladesh increasingly vulnerable and susceptible to cyclonic events.

\subsection{Climate induced migration}

Recent modeling studies concerning the climatic impact of increased greenhouse gas concentrations suggest a discernible warming of the global surface temperature of the planet (Houghton et al., 1992). The overall impacts are now imposed on the people of low lying countries of South Asia like Bangladesh, who are the worst victims of climate change impacts, in spite of their minimal contribution to global warming. Thus, natural disasters exacerbated by climate change increases the number of climate induced migrants or refugees from coastal parts of the country to inland areas either temporarily or permanently (Azam and Sarker, 2010). Climate experts of IIT Madras in their report "Blue Alert-Climate Migrants in South Asia: Estimates and Solutions" estimate that the number of people who could be displaced from their homes due to climate change are 125 million in India and Bangladesh alone. This Report warns that if greenhouse gas emissions continue to grow, under the projected business-as-usual scenario, this would lead to a global temperature rise of $4-5^{\circ} \mathrm{C}$. This would cause the South Asian region to face a wave of migrants displaced by the impacts of climate change, including sea level rise and drought associated with shrinking water supplies and monsoon variability (Rajan, 2008). A survey conducted by Prodipan, (2006) and Save the Children, UK, in the slum areas of Khulna, Bangladesh, revealed that 52 percent of the slum dwellers are environmental refugees, from the most vulnerable southwestern coastal regions of Bangladesh. A majority of the slum dwellers also reported that they were forced to change their occupation and many even had to leave their home due to natural disasters like SIDR. In 2002, approximately 1.0 million people were homeless and more than 1.0 million became refugees due to natural calamities (BDPC, 2003).

\subsection{Climate change mitigation}

Prevention of tropical cyclones is impossible, however, the anthropogenic factors are increasing tropical cyclone intensities and amplifications in tidal surge heights may be mitigated through applying the precautionary principle, introducing effective risk management, and greenhouse gas reduction strategies. The increasing threats of climate-related disasters can be addressed collectively if the global community agrees to contain climate change below recommended thresholds concerning $\mathrm{CO}_{2}$ emissions and atmospheric concentration. Mitigation, as defined by the UNFCCC, appears to be an urgent task and appropriate commitments must be implemented within a decade or so. Unfortunately, although the evidence in 


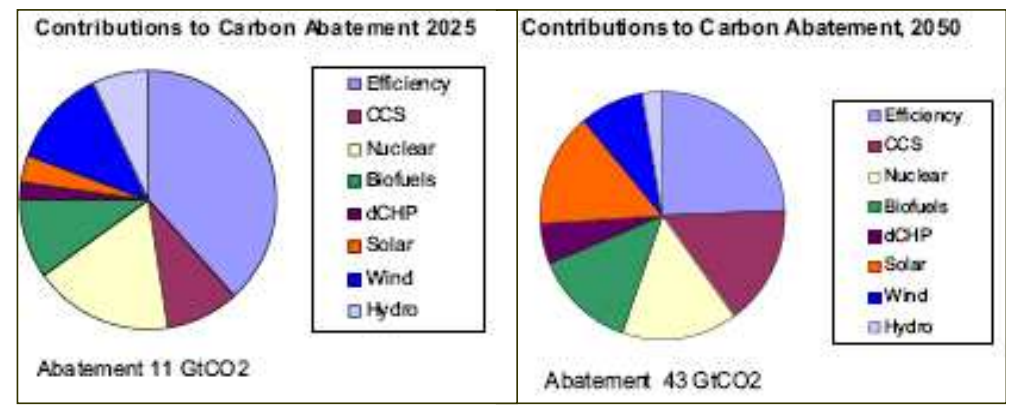

Figure 3 Carbon abatement potential in various sectors in 2025 and 2050 (Source: Stern, 2006).

favour of climate change is quite clear, commitments to reduce emissions are still undecided, as seen in the most recent climate change conference in Cancun, 2010. Since 'dangerous climate change' is looming large and set to occur within the next two decades, the global community must reach an agreement and work collectively to reduce GHG emissions. The Stern Review (Stern et al., 2006) placed an emphasis on the 'benefits of strong, early action on climate change' that outweigh the costs. The review also suggested a key mitigation strategy would be taking strong action to reduce emissions, which must be viewed as an investment, a cost incurred now and in the coming few decades to avoid the risks of very severe consequences in the future'. The Stern review's distribution of emission savings by technology are shown in Fig. 3.

The book 'Factor Five: Transforming the Global Economy through $80 \%$ Increase in Resource Productivity' suggests that sustainable development can be achieved by increasing resource productivity through efficiency improvements for entire sectors of the economy, without reducing quality of services or well-being (von Weizsäcker, 2009).

\section{Disaster Management and Adaptation in the Coastal Areas of Bangladesh}

Adaptation refers to adjustments in ecological-social-economic systems in response to actual or expected climatic stimuli, and their effects or impacts. The ability to adapt and cope is a function of the following: wealth/income, technology, scientific and technical knowledge/skills, information, infrastructure, policy and management institutions, and equity (Chatterjee and Huq, 2002). The remote coastal people of Bangladesh have suffered from recurrent devastating cyclones since ancient times (Ahsan and Azam, 2007). The lessons learnt from SIDR will be useful for increasing overall preparedness for future cyclone events and as a result, will contribute to the harmonization of adaptation processes with ongoing development initiatives. Effective adaptive responses to climate change include 
measures such as: efficient mechanisms for disaster management (including early warning systems); multipurpose building construction; cluster housing patterns; house fortification; plantations; diversification of livelihoods; and the creation of support and extension services to improve or change agricultural practices.

After the devastating flood of 1988 in Bangladesh, the government resettled the people affected by the flood into cluster villages. The concept of cluster villages involved the relocation of a group of flood affected people whose land was eroded by the flood. These people were re-settled on government owned land and provided with housing, water and sanitary facilities. Unfortunately this initiative failed due to inadequate site selection, political bias and inadequate income sources. However, vulnerable people from coastal districts could be resettled in cluster villages with some adjustments through a community consultation process.

Early warning systems in Bangladesh are still very much in the research and development phase. The Bangladesh Disaster Preparedness Centre (BDPC) has conducted studies into the capacity and methods for community based flood warning systems. Early warning systems are a major component of disaster risk reduction and management because they aid vulnerable local disaster managers and communities in preparing for and adapting to disaster events. These warning systems need effective community based dissemination mechanisms and a recent project, undertaken by the BDPC and ActionAid, involved the installation of a pilot community-based flood warning system. The system incorporates community education, warning flags, flood markers, flood risk maps and SMS warnings.

Multipurpose cyclone shelters, which were built mainly after the cyclone of 1991, were found to be useful in flood events and in the small intense cyclone events of 1991 onwards. At present, about 15 percent of the coastal population is under the coverage of cyclone shelter centres, however, this should be extended to the rest of the coastal population (85 percent of the population) to ensure their safety. To perform this extension, 14,220 multipurpose cyclone shelters would be needed (Sarwar, 2005). Multi-uses of buildings (mosque, cyclone shelter, UP office, livestock shelter) should be encouraged in cyclone affected areas (Murtaza and Swapan, 2008).

There are 28,564 educational institutes in the coastal zone including primary, junior and secondary high schools and most of them are either single storey buildings or tin-shed constructions. On the basis of their location in the disaster prone areas, most of the schools should be upgraded to three-storey buildings that are strong enough to tolerate cyclonic winds and storm surges. Disaster affected coastal people could then take shelter in these schools in the event of a cyclone, which could save their lives. There are about 190 man-made highlands in the zone, locally known as killas ${ }^{\text {vii }}$ where livestock are kept safely during disasters. The number of killas should be increased according to the proportion of livestock. Existing cyclone shelters and killas are not well connected with road communication and in some cases, they are in remote areas. Their remoteness means 


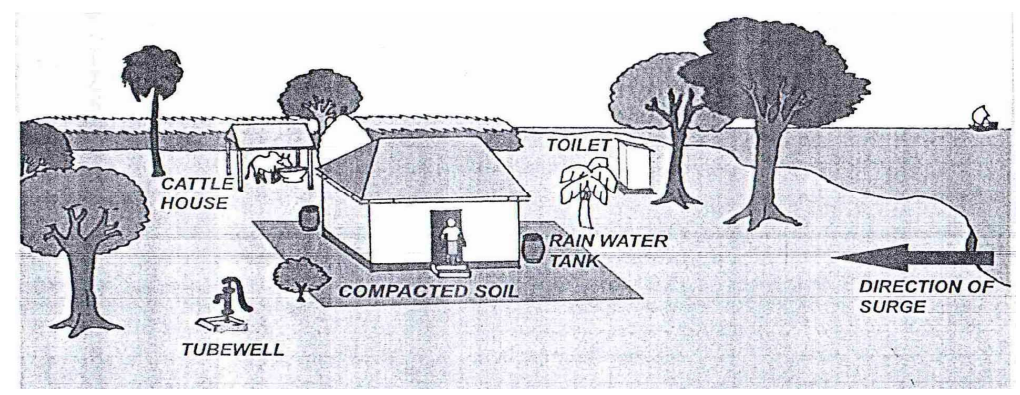

Figure 4 Right position of house near a cyclone and storm surge prone area (SCG, 2008).

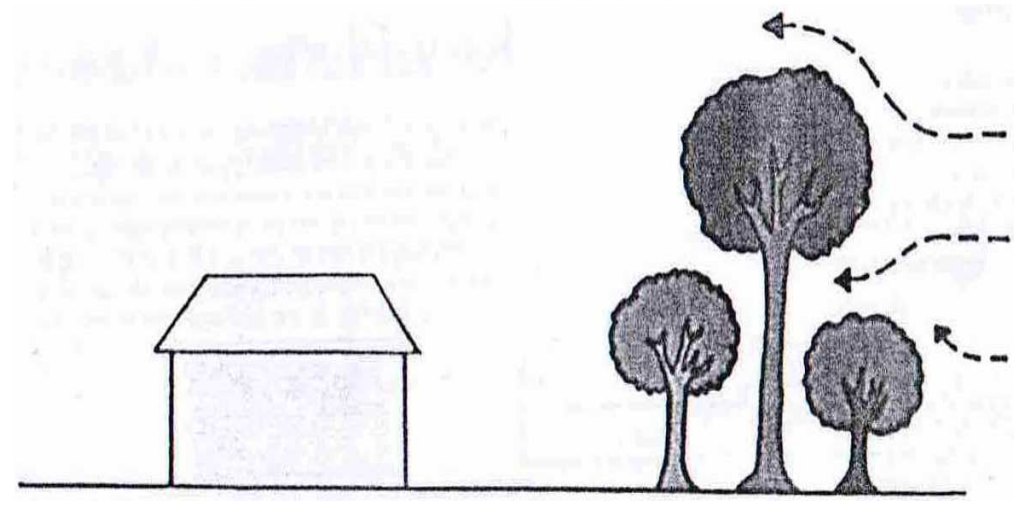

Figure 5 High and medium types tree reducing effects of storm (SCG, 2008).

people or livestock have problems travelling to the centers in case of emergencies, particularly because current road infrastructure makes access to cyclone shelters unmanageable for much of the population. As such, necessary roads should be constructed in order to provide easy access to shelters. Further, plantations of trees, and strategic house placement and fortifications are necessary tools for the protection of dwellings and resources. For houses, their shorter side should be parallel to the bank of a river or the coast (Fig. 4). Coconut trees are common in coastal areas, as well as medium size trees (Mango, Jackfruit, Guava, Papaya, Banana etc.), and can be planted at the boundary of houses to reduce storm impacts (Fig. 5). The house should be constructed on a raised and prepared (level) plinth, at a safe distance from the trees. Rainwater harvesting tanks can supply drinking water and help protect raised plinths from being washed away by rain.

The model cyclone fortified house (Fig. 6) was designed by the Disaster Prevention in the Context of Climate Change (DPCC) Project of Prodipan and was provided to the selected vulnerable people of south western coastal region. It is a cyclone fortified house design that will tolerate wind speeds up to $160 \mathrm{~km} / \mathrm{hr}$, but not cyclones on the scale of SIDR. However, introducing some extra protec- 


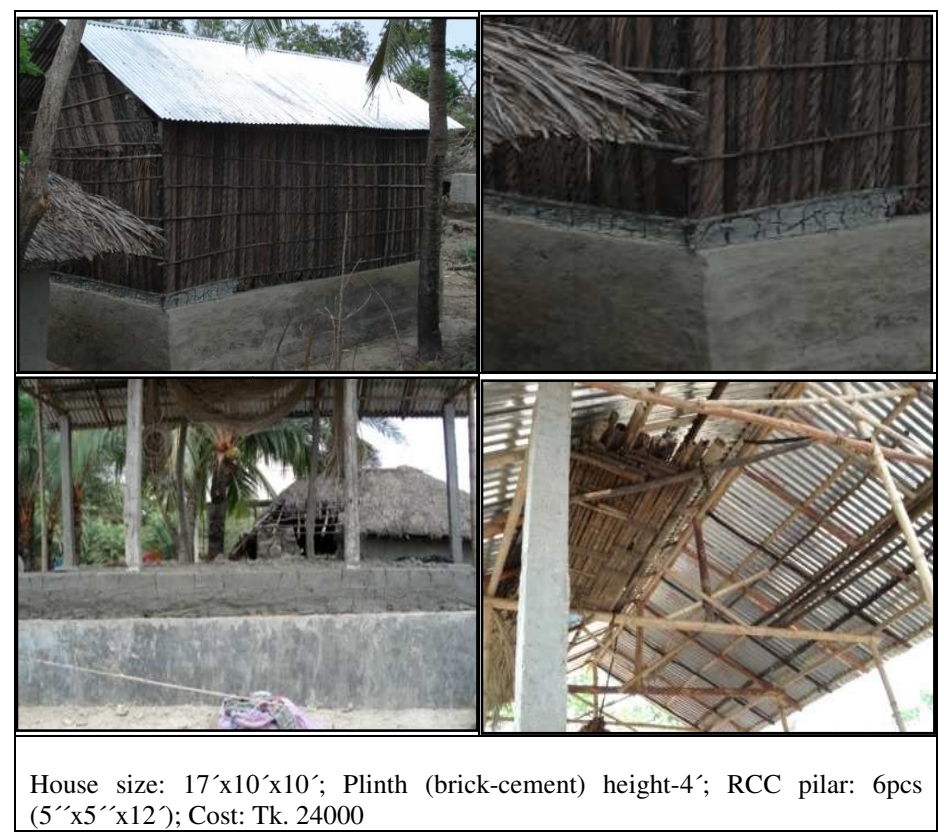

Figure 6 Cyclone fortified house model (Prodipan, 2007).

tion measures can substantially protect houses from cyclones through a mix of indigenous technologies and proven structural techniques.

In this section, we discuss some causes of damage to house structures during cyclones and identifiy some options using indigenous technologies to minimize the damaging effects of storms. The main causes behind the weakening of house structures during cyclone are: (1) mud plinths being washed away (2) incorrect angling of the base and roofing pattern; (3) thatched houses with limited framing; and (4) the roof not being properly tied to either the base or main structure. To cope with cyclones, local people in coastal areas have used some low-cost protection measures since ancient times to reduce the damage and costs at the household and community level. Some indigenous knowledge practiced by local communities in coastal areas is also presented here (Ahsan and Azam, 2007).

Using locally available materials for extra golpata, ${ }^{\text {viii }}$ a fence is built in front of the boundary wall made of mud (up to $6 \mathrm{ft}$ ), palm leaves and thatched fencing to reduce decay and collapse of mud walls due to rainfall and direct wind pressure. Cyclone proofing by coir net, straw net, or fishing net, and bamboo or wattle frames can help make roofs more durable and strong, meaning that storms cannot destroy these roofs easily. Roof protection can defend against wind speeds only in depression time during cyclonic storms (wind speed up to $80-90 \mathrm{~km} / \mathrm{hr}$ ). For tin roofed houses, rope tied from the roof to the structure and soil base can defend against severe cyclonic conditions with wind speeds up to $100-130 \mathrm{~km} / \mathrm{hr}$. The 


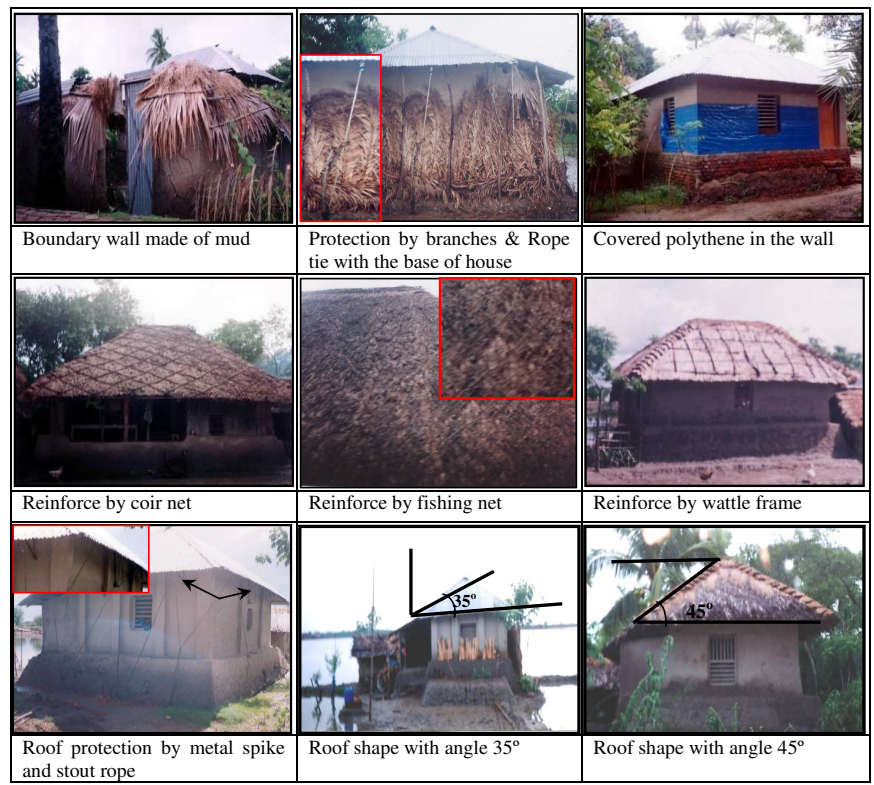

Figure 7 Indigenous knowledge practiced by local communities for the protection from disaster (Ahsan and Azam, 2007).

slope of the roof should not be too steep, otherwise the roof will be prone to a high level of compressive pressure and may collapse. Conversely, a roof with a slope that is too low will be prone to high suction levels and may blow off. Figure 7 represents a roofing slope of $35^{\circ}$ and a slope of $45^{\circ}$, however, to balance the wind load, the slope should actually be between $25^{\circ}$ to $30^{\circ}$ (Ahsan and Azam, 2007).

To improve the livelihoods of peoples in vulnerable communities, the residents should be provided with local-level training, micro-finance programs, and new job opportunities and initiatives, such as training for small scale production or business, creation of a market for local products, and marketing channel development. To this end, several NGOs are now promoting alternative livelihood options among the vulnerable coastal communities. A number of initiatives can be taken in this regard, such as: (1) community based job creation schemes; (2) skill development and training for job seekers and micro-entrepreneurs; (3) encouragement of farm activities such as crab fattening, duck/poultry rearing, goat rearing, apiculture \& honey processing, floating garden/farming, cage aquaculture, vegetable farming at household level, household level nurseries, etc; and (4) providing support to local authorities and stakeholders in creating an enabling environment for micro and small businesses. Finance and adoption of alternative livelihood strategies is an important issue for Bangladesh to adapt to climate change impacts at the local level. To increase domestic financial resources for adaptation purposes, government should raise funds from the coastal zone resources. This is because 
the extent to which these activities will be undertaken depends on institutional capacities in developing countries and on the availability of funding (The World Bank, 2008). This early warning system of dissemination - through awareness campaign, change in agricultural practices and introducing resistant crop varieties - can reduce the severity of damage as well as ensure food security.

\section{Conclusions}

Temperature rise is one of the prime factors of climate change. With the trend of increased emission of Green House Gases (GHGs), the global temperature is increasing with time. Global warming is leading to a raised sea surface temperature (fosters formations of cyclones) and accelerating melting of ice in the polar region. Both of these effects of global warming are directly related with the increasing frequency and intensity of cyclonic storm and tidal surges. The increased frequency and intensity of cyclones give rise to economic, environmental and social impacts and also threatens the food and livelihood security of the population. The damage caused by intense and frequent cyclones mean it is necessary for the people to adapt to the climate change impact. This means mainstreaming climate change adaptation should be obligatory for vulnerable

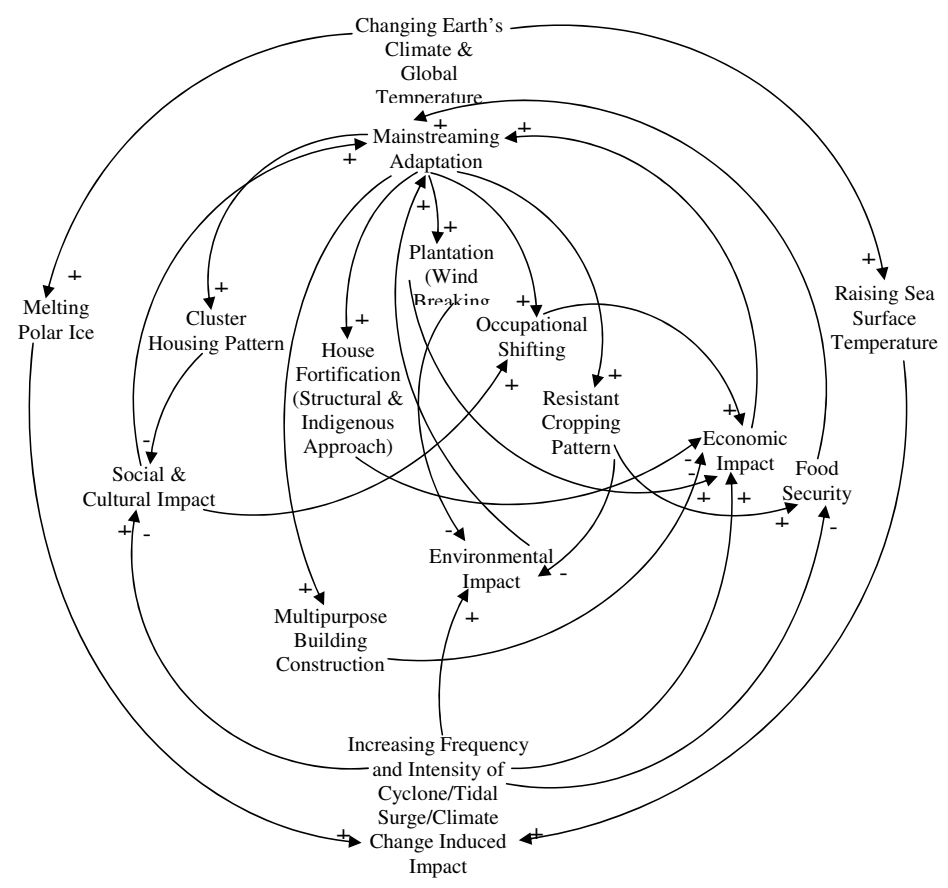

Figure 8 Causal Loop Diagram-Climate change induced impacts and possible adaptive mechanisms. 
people in coastal areas. This can include cluster housing patterns, plantations of wind breaking trees, house fortification using both structural and indigenous approach, multipurpose building construction within the cluster houses, occupational shifting (either alternative livelihoods within the area or engaged in new occupation due to migration in another area) and impact resistant cropping patterns (saline/drought/water logging). All of these adaptive mechanisms can minimize the adverse impact on society, environment and the economy due to climate change, and increase the food security of the local population (Fig. 8). The following causal loop diagram (Fig. 8) illustrates climate change induced impacts and possible adaptive mechanisms. The positive $(+)$ signs in the diagram indicate contributing factors to the impacts of climate change on the environment, economy and society, such as rising SST which will increase the frequency and intensity of cyclones and tidal surges. The negative $(-)$ signs indicate a reduction in the contribution of factors, for example, resistant cropping patterns will impact less on the environment, and cluster housing patterns will reduce the social and cultural impacts of climate change.

It is clear that Bangladesh is seriously affected by climate change impacts, particularly cyclones, tidal surges, sea level rise, changes in temperature and precipitation. Unfortunately, these adverse impacts of climate change will take time to reverse or correct. Accordingly, global communities should adapt methods directed at minimizing the impacts of climate change, especially the damaging results in the form of cyclones and tidal surges. Overall, strategies to minimize the impacts of climate change involve either mitigation or adaptation. However, since polluting countries are yet to reach a consensus on their climate change strategy. Bangladesh needs to consider both mitigation and adaptation options given this lack of global agreement. This is the case despite the fact that Bangladesh has very limited scope for mitigation, and adaptation is still hampered due to inadequate financial resources and institutional capacity. Climate change mitigation requires the coordination of global efforts (global scale) whilst adaptation is a more local approach (local scale). Accordingly, effective adaptation policies and mitigation measures should be developed and implemented to minimize the impacts on vulnerable regions such as, Bangladesh, given the particular severity of the impacts of climate change on the population. If Bangladesh fails to implement adaptation measures carefully, the people in coastal areas will lose their means of subsistence within this century thereby endangering the survival of future generations. As Bangladesh is one of the most densely populated countries in the world, relocation of coastal people to inland regions is not a viable option because of limited land availability. The high population density in Bangladesh lends itself to local level management concerning the impacts of climate change and this should be the first priority. Therefore, the Government of Bangladesh needs to pay keen attention to the issue of climate change and should develop strategies to minimize the impacts of climate change through the development and implementation of adaptive measures and therefore help ensure the safety of its citizens. 


\section{Acknowledgements}

The authors acknowledge the financial and logistical support of Prodipan (a NGO in Bangladesh) for this research.

\section{Notes}

(i) SIDR was derived from the Sinhalese Language where 'SIDR' means 'hole' or 'eye'

(ii) small administrative units of upazilas

(iii) administrative units of districts

(iv) Tk.-Bangladesh currency (1 USD = 73.15 BDT (BDT = Bangladesh Taka, as at Nov 2007))

(v) Madrashas-religious educational institutions

(vi) elevated sandy platform in the river

(vii) killas are elevated earth platform known as livestock shelter

(viii) golpata are thatched materials used as roof

\section{References}

1. Azam, M. and T. Sarker, 2010. In the Eye of Climate Change: Urbanization in Bangladesh. In, International Conference on Urbanization and Global Environmental Change: Opportunities and Challenges for Sustainability in an Urbanizing World, October 15-17, 2010, USA: Arizona State University.

2. Agrawala, S., T. Ota, A. U. Ahmed, J. Smith and M. V. Aalst, 2003. Development and Climate Change in Bangladesh: Focus on Coastal Flooding and the Sundarbans. Paris: OECD.

3. Ahsan, M. M. and M. Azam, 2007. Indigenous Knowledge and Cyclone Preparedness of a Remote Coastal Community in Bangladesh. In, First Conference on Indigenous People and Bangladesh Environment, December 17-18, 2007, Dhaka: IEB.

4. Ali, A. 2000. Vulnerability of Bangladesh Coastal Region to Climate Change with Adaptation Options. Space Research and Remote Sensing Organization, Ministry of Defense, Government of the People's Republic of Bangladesh. Dhaka: SPARRSO.

5. Ali, A. 1999. Climate Change Impacts and Adaptation Assessment in Bangladesh. Climate Research, 12, 109-116.

6. Ali, A. 1996. Vulnerability of Bangladesh to Climate Change and Sea Level Rise through Tropical Cyclones and Storm Surges. Water, Air and Soil Pollution, 94(d), 171-179.

7. BDPC Bangladesh Disaster Preparedness Centre. Adaptation to the Impact of Climate Change through Community based Flood Warning System. Blangladesh Disaster Preparedness Centre. 2011-10-11. URL:http://www.bdpc.org.bd/index.php? option $=$ com_content\&view $=$ article\&id $=76 \% 3$ Aactionaid\&catid $=45 \% 3$ Aprojectspartners\&Itemid=1. Accessed: 2011-10-11. (Archived by WebCite ${ }^{\circledR}$ at http://www. webcitation.org/62LaOMg81).

8. BBS (Bangladesh Bureau of Statistics). 2002. Statistical Yearbook 2002, Ministry of Planning, Government of the People's Republic of Bangladesh. Dhaka: BBS. 
9. BFFEA (Bangladesh Frozen Food Exporters' Association). 2008. Personal Communication. Dhaka, Bangladesh: BFFEA.

10. BMD (Bangladesh Meteorological Department), 2010. Personal Communication, Dhaka, Bangladesh: BMD.

11. BDPC (Bangladesh Disaster Preparedness Centre), 2003. Personal Communication, Dhaka, Bangladesh: BDPC.

12. Chatterjee, R. and S. Huq, 2002. A Report on the Inter-regional Conference on Adaptation to Climate Change. Mitigation and Adaptation Strategies for Global Change, 7(4), 403-406.

13. Charlie Forecast Team, 2007a. November 9 Significant Tropical Weather Advisory for the Indian Ocean. Joint Typhoon Warning Center. Hawaii, USA: JWTC.

14. Charlie Forecast Team, 2007b. November 11 Tropical Cyclone Formation Alert. Joint Typhoon Warning Center. Hawaii, USA: JWTC.

15. EU (European Union), 1998. Draft Final Report on Cyclone Shelter Preparatory Study (CPSP) Stage I: Feasibility Study, 3, European Commission Report, Brussels: EU.

16. Emanuel, K. A. 1987. The Dependence of Hurricane Intensity on Climate. Nature, 326, 483-485.

17. Houghton, J. T., B. A. Callander and S. K. Varney. 1992. Climate Change 1992, the Supplementary Report to the IPCC Scientific Assessment. Intergovernmental Panel on Climate Change (IPCC), Cambridge: Cambridge University Press.

18. ILO (International Labour Organization), 2008. Preliminary Assessment of the Impact of Cyclone SIDR on Decent Employment and Proposed Recovery Strategy. International Labour Office in Bangladesh, Dhaka: ILO.

19. IPCC (Intergovernmental Panel on Climate Change), 2007. Working Group II Contribution to the Intergovernmental Panel on Climate Change Fourth Assessment Report: Summary for Policymakers. Intergovernmental Panel on Climate Change Secretariat, Geneva, Switzerland: IPCC.

20. Islam, R. 2005. Where Land Meets the Sea. Dhaka: University Press Limited.

21. JWTC (Joint Typhone Warning Centre), 2007. Cyclone Best Track Records. Retrieved from http://www.usno.navy.mil/NOOC/nmfc-

ph/RSS/jtwc/best_tracks/2007/2007s-bio/bio062007.txt on March 08, 2008, Hawaii, USA: JWTC.Khan, N. A. and S. Sen. 2000. Of Popular Wisdom: Indigenous Knowledge and Practices in Bangladesh. BARCIK, 147-149.

22. Murtaza, G. M. and M. S. H. Swapan. 2008. Planning and Implementation Aspects of a Model Village Plan Located in the SIDR Affected Area-A Study of Southkhali, Sharonkhola Upazila, Bagerhat District. Urban and Rural Planning Discipline, Khulna: Khulna University.

23. MoFDM (Ministry of Food and Disaster Management), 2007a. Official Damage Report by Cyclone SIDR 2007. Government of the People's Republic of Bangladesh, Dhaka: MoFDM.

24. MoFDM (Ministry of Food and Disaster Management), 2007b. Draft National Plan for Disaster Management 2007-2015. Government of the People's Republic of Bangladesh, Dhaka: MoFDM.

25. NSIDC (National Snow and Ice Data Center), 2008. Satellite Image of Wilkins Ice Shelf Disintegration-March 8, 2008. University of Colorado, Boulder, USA: NSIDC.

26. Prodipan, 2008. Damage Assessment Report of Cyclone SIDR 2007. Prodipan-A Non Governmental Organization, Khulna.

27. Prodipan, 2007. Disaster Prevention in the Context of Climate Change (DPCC) Project. Prodipan-A Non Governmental Organization, Khulna.

28. Rahman, P. 2007. Cyclone Death Toll up to 3,100 in Bangladesh, May Rise. Associated Press, National Geographic News. Retrieved from http://news.national geographic.com/news/2007/11/071119-AP-bangladesh-cyclone.html on March 20, 2008. 
29. Rajan, S. C. 2008. Blue Alert-Climate Migrants in South Asia: Estimates and Solutions. Greenpeace Web Publications, Retrieved from <http://www.greenpeace.org/india> on March 30, 2008.

30. ReliefWeb, 2011. Briefing Kit for Xinhua+Bangladesh Compiled on June 03, 2011. Retrieved from http://reliefweb.int/sites/reliefweb.int/files/reliefweb_pdf/briefingkitfd25abf43fd2976f0811ba66719f19c8.pdf on June 03, 2011.

31. REB (Rural Electrification Board), 2008. Personal Communication. Dhaka, Bangladesh: REB.

32. Royer, J. F., F. Chauvin, B. Timbal, P. Araspin and D. Grimal 1998. A GCM Study of the Impact of Greenhouse Gas Increase on the Frequency of Occurrence of Tropical Cyclones. Climatic Change, 38(3), 307-343.

33. SCG (Shelter Coordination Group), 2008. Construction Manual on Shelters for Cyclone-prone Coastal Areas of Bangladesh. United Nations Development Programme, Bangladesh: SCG.

34. SPARRSO (Space Research and Remote Sensing Organization), 2007. Satellite Image of Cyclone SIDR 2007. Ministry of Defense, Government of the People's Republic of Bangladesh, Dhaka: SPARRSO.

35. SMRC, 1999. from CEGIS (Center for Environmental and Geographic Information Services), 2006. Impact of Sea Level Rise on Landuse Suitability and Adaptation Options. Bangladesh: SMRC.

36. Stern, N., S. Peters, V. Bakhshi, A. Bowen, C. Cameron, S. Catovsky, D. Crane, S. Cruickshank, S. Dietz, N. Edmonson, S.-L. Garbett, L. Hamid, G. Hoffman, D. Ingram, B. Jones, N. Patmore, H. Radcliffe, R. Sathiyarajah, M. Stock, C. Taylor, T. Vernon, H. Wanjie and D. Zenghelis, 2006. Stern Review: The Economics of Climate Change, London: HM Treasury.

37. Sarwar, M. G. M. 2005. Impacts of Sea Level Rise on the Coastal Zone of Bangladesh, MSc Thesis, Lund University International Masters Program in Environmental Science and Sustainability Studies, Lund University, Sweden: LUND.

38. The Daily Ittefaq, 2008. Report on Cyclone SIDR. The Daily Ittefaq, January 08, 2008.

39. The Daily Star, 2007. SIDR starts pounding coastline. The Daily Star, November 15, 2007.

40. UNDP (United Nations Development Programme), 2008. Response and Action Plan Report of Cyclone SIDR 2007. Bangladesh: UNDP.

41. Webcite, 2007a. DEMS-RSMC Tropical Cyclone New Delhi, Dated 12-11-2007. Retrieved from http:/ / www.webcitation.org/5TIfWlbW7 on March 08, 2008.

42. Webcite, 2007b. DEMS-RSMC Tropical Cyclone New Delhi, Dated 13-11-2007. Retrieved from http:/ / www.webcitation.org/5TJAaMgwa on March 08, 2008.

43. Webcite, 2007c. DEMS-RSMC Tropical Cyclone New Delhi Dated 15-11-2007. Retrieved from http:/ / www.webcitation.org/5TN5iJn0i on March 08, 2008.

44. Webcite, 2007d. Last Bulletine, Dated 16-11-2007. Retrieved from http:/ /www.webcitation.org/5TOxxpK5w on March 08, 2008.

45. The World Bank, 2008. Global Monitoring Report 2008, MDGs and the Environment: Agenda for Inclusive and Sustainable Development, Washignton, DC: World Bank.

46. Wigley, T. M. L. and S. C. B. Raper, 1987. Thermal Expansion of Sea Water Associated with Global Warming. Nature, 357, 293-300.

47. von Weizsäcker, E. U., K. Hargroves, M. Smith, C. Desha and P. Stasinopoulos, 2009. Factor 5: Transforming the Global Economy through 80\% Increase in Resource Productivity. Earthscan: UK and Droemer: Germany. 